\title{
Potencial alelopático de espécies nativas na germinação e crescimento inicial de Lactuca sativa L. (Asteraceae) ${ }^{1}$
}

\author{
Fabiana Maraschin-Silva ${ }^{2,3}$ e Maria Estefânia Alves Aqüila²
}

Recebido em 09/11/2004. Aceito em 24/06/2005.

\begin{abstract}
RESUMO - (Potencial alelopático de espécies nativas no processo de germinação e crescimento inicial de Lactuca sativa L. (Asteraceae)). A alelopatia caracteriza-se pelos efeitos danosos ou benéficos sobre o desenvolvimento da vegetação, causados por substâncias químicas produzidas e liberadas para o ambiente por uma planta. Com o objetivo de avaliar o potencial alelopático de espécies brasileiras, foram testados extratos foliares de Cecropia pachystachya Trec. (Urticaceae), Peltophorum dubium (Spreng.) Taub. (Fabaceae), Psychotria leiocarpa Cham. \& Schltdl (Rubiaceae), Sapium glandulatum (Vell.) Pax (Euphorbiaceae) e Sorocea bonplandii (Baill.) Burg., Lanj. \& Boer (Moraceae), utilizando-se bioensaios de germinação e crescimento e alface (Lactuca sativa L.) como planta alvo. Nesses bioensaios, foram usados extratos foliares aquosos nas concentrações de 2 e $4 \%$, preparados por maceração estática com água fria e quente. Os extratos das cinco espécies causaram atraso na germinação dos aquênios da alface, bem como efeitos tóxicos no crescimento das plântulas, com redução e enfraquecimento das raízes. Os resultados obtidos mostraram a presença de substâncias químicas inibidoras nos extratos, revelando potencial alelopático para as cinco espécies avaliadas.
\end{abstract}

Palavras-chave : Cecropia pachystachya, Peltophorum dubium, Psychotria leiocarpa, Sapium glandulatum, Sorocea bonplandii, alelopatia

\begin{abstract}
Allelopathic potential of native species in Lactuca sativa L. (Asteraceae) germination and initial growth). Allelopathy is characterized by harmful or beneficial effects on vegetation development, caused by chemical substances produced and released into the environment by the plant. Aiming to assess the allelopathic potential of Brazilian species, aqueous leaf extracts of Cecropia pachystachya Trec. (Urticaceae), Peltophorum dubium (Spreng.) Taub. (Fabaceae), Psychotria leiocarpa Cham. \& Schltdl (Rubiaceae), Sapium glandulatum (Vell.) Pax (Euphorbiaceae), and Sorocea bonplandii (Baill.) Burger, Lanj. \& Boer (Moraceae) were tested on lettuce using germination and growth bioassays. In these bioassays, aqueous leaf extracts were used at concentrations of 2 and $4 \%$, prepared by static maceration with cold and hot water. The five species extracts delayed lettuce germination and produced toxic effects on seedling growth, with root reduction and debility. The results point to the presence of inhibitorychemical substances in the extracts, indicating an allelopathic potential for the five species evaluated.
\end{abstract}

Key words: Cecropia pachystachya, Peltophorum dubium, Psychotria leiocarpa, Sapium glandulatum, Sorocea bonplandii, allelopathy

\section{Introdução}

Os vegetais liberam no ambiente diversos metabólitos primários e secundários que podem influenciar no desenvolvimento da vegetação adjacente, sendo este fenômeno de interferência denominado alelopatia, conforme discutido por Rice (1984). A liberação destas substâncias químicas para o meio ambiente, denominadas aleloquímicos, pode ocorrer de várias maneiras. Entre as rotas de liberação incluemse a volatilização pelas partes aéreas da planta; a lixiviação das superfícies do vegetal através da chuva, orvalho e neblina; a exsudação pelas raízes; a decomposição de resíduos vegetais e a lixívia de serapilheira (Whittaker \& Feeny 1971; Chou 1986; Anaya 1999).
A decomposição de resíduos vegetais destaca-se como a fonte de aleloquímicos mais importante; entretanto, esse processo de liberação não é uniforme, variando conforme o ecossistema (Reigosa et al. 1999).

Os aleloquímicos podem apresentar ação direta ou indireta sobre a planta alvo. Alterações nas propriedades e características nutricionais do solo e também nas populações e/ou atividade de organismos que habitam o solo são consideradas como efeitos indiretos. Os efeitos diretos, por sua vez, são mais estudados e compreendem alterações celulares e metabólicas, incluindo modificações no funcionamento de membranas, na absorção de nutrientes e de água, na atividade fotossintética e respiratória, entre outras (Rice 1984; Rizvi et al. 1992; Reigosa et al. 1999). As

\footnotetext{
1 Parte da Dissertação de Mestrado da primeira Autora. Apoio financeiro CAPES

2 Universidade Federal do Rio Grande do Sul, Programa de Pós-Graduação em Botânica, Av. Bento Gonçalves, 9500, Prédio 43.433, Sala 214 CEP 91501-970, Porto Alegre, RS, Brasil

3 Autor para correspondência: fabimaraschin@terra.com.br
} 
saponinas, os taninos e os flavonóides estão entre os aleloquímicos comumente citados como responsáveis por causarem efeitos diretos e indiretos, podendo ser liberados em condições naturais, já que são hidrossolúveis (Rice 1984; Ferreira \& Aqüila 2000).

Em função dessas alterações, a alelopatia é reconhecida como um processo ecológico importante em ecossistemas naturais e manejados, influenciando na sucessão vegetal primária e secundária, na estrutura, composição e dinâmica de comunidades vegetais nativas ou cultivadas (Chou 1986; Rizvi et al. 1992; Reigosa et al. 1999; Scrivanti et al. 2003). Neste último caso, os aleloquímicos são vistos como alternativas a agroquímicos sintéticos, objetivando o manejo sustentável e ecológico na produção agrícola. Muitas substâncias alelopáticas apresentam grande potencial para uso no controle biológico de ervas daninhas (Putnam \& Duke 1974; Macharia \& Peffley 1995; Anaya 1999; Chou 1999; Chung et al. 2001), sendo parcial ou totalmente solúveis em água e ativas em baixas concentrações (Vyvyan 2002). Em contrapartida ao poder fitotóxico, os efeitos de promoção da germinação e do crescimento vegetal causados por aleloquímicos também são de interesse para o manejo agrícola (Vyvyan 2002).

Apesar desses estudos, o conhecimento da ação alelopática de espécies nativas ainda é incipiente no Brasil, considerando-se a extensão territorial e a diversidade florística (Ferreira et al. 1992). Em vista disto, a ampliação desse conhecimento para a flora brasileira é de grande importância. O presente estudo teve como objetivo avaliar o potencial alelopático de Cecropia pachystachya Trec. (Urticaceae), Peltophorum dubium (Spreng.) Taub. (Fabaceae), Psychotria leiocarpa Cham. \& Schltdl (Rubiaceae), Sapium glandulatum (Vell.) Pax (Euphorbiaceae) e Sorocea bonplandii (Baill.) Burger, Lanj. \& Boer (Moraceae) na germinação e crescimento inicial de Lactuca sativa L. (Asteraceae), por meio de bioensaios laboratoriais.

\section{Material e métodos}

Como material vegetal, foram usadas folhas adultas de cinco indivíduos de Cecropia pachystachya, Peltophorum dubium, Psychotria leiocarpa, Sapium glandulatum e Sorocea bonplandii, coletadas em áreas com vegetação natural do Campus do Vale da Universidade Federal do Rio Grande do Sul, UFRGS, Porto Alegre, RS. Como espécie alvo, foi utilizada alface (Lactuca sativa cv. Branca Boston), cujos aquênios foram obtidos no comércio local. As folhas coletadas foram secas durante 10 dias à temperatura ambiente $\left(25^{\circ} \mathrm{C}\right)$ e os extratos foram preparados empregando-se o método de maceração estática (Soares \& Vieira 2000). Foi feita uma extração usando água quente, na qual as folhas inteiras foram imersas em água destilada, com temperatura inicial aproximada de $80{ }^{\circ} \mathrm{C}$, nas concentrações de 2 e $4 \%$ (massa/ volume), sendo mantidas na mesma água, resfriada naturalmente, até completar $24 \mathrm{~h}$, não havendo controle nas condições de iluminação durante a extração (Aqüila 2000). Posteriormente, os extratos foram filtrados em funil forrado com gaze, seguindo-se centrifugação à $1308 x$ g por 10 minutos, sendo os sobrenadantes utilizados diretamente nos bioensaios. Adicionalmente, foram preparados extratos a frio, nos quais as folhas inteiras foram imersas em água destilada fria na concentração de $10 \%$ (massa/volume), sendo mantidas à $8{ }^{\circ} \mathrm{C}$, no escuro, por $24 \mathrm{~h}$ (Rutherford \& Powrie 1993). Após este período, o material foi filtrado e centrifugado, seguindo os mesmos procedimentos citados acima, sendo o sobrenadante diluído para se obter as soluções a 2 e $4 \%$, que foram empregadas nos bioensaios. Os extratos foram caracterizados quanto ao $\mathrm{pH}$, aferido com pHmetro ou papel indicador; potencial osmótico, estimado pelo método de Chardakov (Salisbury \& Ross 1992) e quanto ao resíduo. Este foi determinado após a evaporação total em estufa $\left(60{ }^{\circ} \mathrm{C}\right)$, de $3 \mathrm{~mL}$ de extrato colocado em tubo de ensaio. $\mathrm{O}$ cálculo foi baseado na razão entre a diferença de massas inicial e final do tubo de ensaio e o volume de extrato utilizado, sendo seu resultado expresso em $\mathrm{mg} \mathrm{mL}^{-1}$. Também foram feitas reações de detecção de flavonóides, saponinas e taninos (Falkenberg et al. 2003), usandose extratos a 5\% (peso/volume), preparados com o pó das folhas secas e água destilada, mantendo-se em banho-maria fervente por 15 minutos, para se obter maior extração de substâncias químicas.

O bioensaio de germinação foi conduzido em placas de Petri $(9 \mathrm{~cm})$, forradas com papel de filtro umedecido com $6 \mathrm{~mL}$ dos extratos ou água destilada (controle). Foram semeados 20 aquênios de alface por placa, que foram mantidas em câmara de germinação à $25^{\circ} \mathrm{C}$, fotoperíodo de $12 \mathrm{~h}$ e irradiância de $45 \mu \mathrm{mol} \mathrm{m} \mathrm{s}^{-2}$, durante $96 \mathrm{~h}$. Para evitar evaporação dos extratos ou água destilada, as placas foram seladas com filme de PVC. O registro do número de aquênios germinados foi feito a cada $12 \mathrm{~h}$, sendo que o critério de avaliação da germinação foi a curvatura geotrópica da raiz, como indicado por Ferreira \& Aqüila (2000). A viabilidade dos aquênios que não germinaram ao final de $96 \mathrm{~h}$ foi avaliada pelo teste do tetrazólio (Brasil 1992). 
Com os dados obtidos no bioensaio, foram calculados, para cada unidade experimental (placa de Petri), a germinabilidade, o tempo médio de germinação e a entropia informacional da germinação, de acordo com Labouriau (1983).

Para padronizar o tamanho das plântulas a serem tratadas com os extratos no bioensaio de crescimento, os aquênios de alface foram colocados para germinar em placa de Petri, forrada com papel de filtro umedecido com água destilada $(6 \mathrm{~mL})$, e mantida em câmara de germinação por $24 \mathrm{~h}$ nas condições descritas acima. Posteriormente, as plântulas, com $1 \mathrm{~mm}$ de raiz, foram transferidas para placas de Petri $(9 \mathrm{~cm})$, forradas com papel de filtro umedecido com $6 \mathrm{~mL}$ dos extratos ou água destilada, perfazendo 10 plântulas por placa. As placas, seladas com filme de PVC, foram incubadas em câmara de germinação, nas mesmas condições descritas para o bioensaio de germinação. Após seis dias, o comprimento do hipocótilo e da raiz das plântulas foram medidos, calculando-se as médias para cada unidade experimental (placa de Petri), sendo também registrado o aspecto geral das plântulas em cada tratamento.

Foi utilizado o delineamento experimental em blocos casualizados, com cinco tratamentos (um controle + quatro extratos). Cada tratamento teve seis repetições no bioensaio de germinação e 12 repetições no de crescimento, totalizando 120 aquênios por tratamento em cada bioensaio. Os dados foram submetidos a testes de hipóteses por meio da análise da variância $(\alpha=0,05)$, cujo resultado, independente do tipo de distribuição, foi submetido a testes de aleatorização e auto-reamostragem (bootstrap) (Manly 1991; Pillar \& Orlóci 1996), utilizando-se o programa MULTIV versão 2.1.1 (Pillar 2001).

\section{Resultados}

Ao final de 96 h, a germinabilidade dos aquênios de alface submetidos à ação dos extratos foliares das cinco espécies estudadas não mostrou diferença significativa em relação ao tratamento controle (Tab. 1). Por outro lado, o tempo médio de germinação foi reduzido por alguns extratos de todas as espécies

Tabela 1. Efeito de extratos foliares aquosos de espécies nativas na germinação de aquênios de alface. ${ }^{1}$

\begin{tabular}{|c|c|c|c|c|}
\hline & Bioensaio & $G(\%)$ & $\bar{t}(\mathrm{~h})$ & $\bar{E}$ (bits) \\
\hline \multirow[t]{5}{*}{ Cecropia pachystachya } & Controle & $95,00 \pm 6,324 \mathrm{ab}$ & $32,070 \pm 3,182 \mathrm{a}$ & $1,184 \pm 0,131 \mathrm{a}$ \\
\hline & EF $2 \%$ & $96,67 \pm 4,082 \mathrm{a}$ & $37,592 \pm 3,761 \mathrm{ab}$ & $1,749 \pm 0,328 b$ \\
\hline & $\mathrm{EF} 4 \%$ & $92,50 \pm 8,216 \mathrm{ab}$ & $35,945 \pm 5,303 a b$ & $1,576 \pm 0,267 \mathrm{ab}$ \\
\hline & EQ $2 \%$ & $94,17 \pm 3,764 a b$ & $36,525 \pm 4,428 a b$ & $1,654 \pm 0,405 \mathrm{ab}$ \\
\hline & EQ 4\% & $89,17 \pm 5,845 b$ & $40,958 \pm 3,030 \mathrm{~b}$ & $1,999 \pm 0,258 \mathrm{~b}$ \\
\hline \multirow[t]{5}{*}{ Peltophorum dubium } & Controle & $94,17 \pm 2,041 \mathrm{a}$ & $22,030 \pm 1,622 \mathrm{a}$ & $0,958 \pm 0,187 \mathrm{a}$ \\
\hline & EF $2 \%$ & $97,50 \pm 4,183 \mathrm{a}$ & $24,277 \pm 2,071 a b$ & $0,792 \pm 0,370 \mathrm{a}$ \\
\hline & $\mathrm{EF} 4 \%$ & $94,17 \pm 3,764 \mathrm{a}$ & $26,037 \pm 1,822 b$ & $0,867 \pm 0,236 \mathrm{a}$ \\
\hline & EQ $2 \%$ & $96,67 \pm 4,082 \mathrm{a}$ & $26,254 \pm 1,706 b$ & $1,025 \pm 0,237 \mathrm{a}$ \\
\hline & EQ $4 \%$ & $95,00 \pm 5,477 \mathrm{a}$ & $25,714 \pm 2,341 \mathrm{~b}$ & $0,736 \pm 0,456 a$ \\
\hline \multirow[t]{5}{*}{ Psychotria leiocarpa } & Controle & $93,33 \pm 5,164 \mathrm{a}$ & $28,109 \pm 1,431 \mathrm{a}$ & $0,897 \pm 0,135 \mathrm{a}$ \\
\hline & EF $2 \%$ & $95,00 \pm 3,162 \mathrm{a}$ & $30,359 \pm 3,366 \mathrm{a}$ & $1,207 \pm 0,361 \mathrm{ab}$ \\
\hline & $\mathrm{EF} 4 \%$ & $96,67 \pm 2,52$ a & $32,026 \pm 4,063 \mathrm{ab}$ & $1,416 \pm 0,334 \mathrm{~b}$ \\
\hline & EQ $2 \%$ & $90,83 \pm 4,916 \mathrm{a}$ & $30,983 \pm 5,068 \mathrm{ab}$ & $1,114 \pm 0,441 \mathrm{ab}$ \\
\hline & EQ $4 \%$ & $92,50 \pm 6,124 \mathrm{a}$ & $35,826 \pm 5,327 b$ & $1,552 \pm 0,371 \mathrm{~b}$ \\
\hline \multirow[t]{5}{*}{ Sapium glandulatum } & Controle & $93,33 \pm 5,164 \mathrm{a}$ & $28,109 \pm 1,431 \mathrm{a}$ & $0,897 \pm 0,135 a$ \\
\hline & EF $2 \%$ & $90,83 \pm 4,916 \mathrm{a}$ & $29,365 \pm 1,596 \mathrm{a}$ & $1,172 \pm 0,255 \mathrm{ab}$ \\
\hline & $\mathrm{EF} 4 \%$ & $90,00 \pm 4,472 \mathrm{a}$ & $31,101 \pm 1,088 \mathrm{a}$ & $1,295 \pm 0,144 \mathrm{bc}$ \\
\hline & EQ $2 \%$ & $90,83 \pm 5,845 \mathrm{a}$ & $30,003 \pm 2,185 a$ & $1,151 \pm 0,209 \mathrm{ab}$ \\
\hline & EQ 4\% & $91,67 \pm 6,055 \mathrm{a}$ & $36,397 \pm 1,925 b$ & $1,519 \pm 0,196 \mathrm{c}$ \\
\hline \multirow[t]{5}{*}{ Sorocea bonplandii } & Controle & $96,67 \pm 4,082 a b$ & $23,584 \pm 0,984 a$ & $0,636 \pm 0,197 a$ \\
\hline & EF $2 \%$ & $97,50 \pm 4,183 a$ & $25,922 \pm 1,900 \mathrm{ab}$ & $0,765 \pm 0,295 a$ \\
\hline & $\mathrm{EF} 4 \%$ & $98,33 \pm 2,582 \mathrm{a}$ & $25,958 \pm 2,152 a b$ & $0,649 \pm 0,219 a$ \\
\hline & EQ $2 \%$ & $97,50 \pm 4,183$ a & $26,816 \pm 2,494 a b$ & $0,700 \pm 0,424 a$ \\
\hline & EQ $4 \%$ & $90,00 \pm 7,071 b$ & $28,652 \pm 4,607 b$ & $0,767 \pm 0,250 a$ \\
\hline
\end{tabular}

${ }^{1}$ Média \pm desvio padrão. EF $2 \%$ : extrato foliar extraído a $8{ }^{\circ} \mathrm{C}$, diluído em água a $2 \%$; EF $4 \%$ : extrato foliar extraído a $8{ }^{\circ} \mathrm{C}$, diluído em água a $4 \%$; EQ 2\%: extrato foliar aquoso a $2 \%$, extraído à temperatura inicial de $80^{\circ} \mathrm{C}$; EQ $4 \%$ : extrato foliar aquoso a $4 \%$, extraído à temperatura inicial de $80^{\circ} \mathrm{C} ; G$ : germinabilidade após $96 \mathrm{~h} ; \bar{t}$ : tempo médio de germinação; $\bar{E}$ : entropia informacional da germinação. Médias seguidas por letras iguais na vertical, dentro de cada bioensaio, não diferem entre si $(\mathrm{p} \leq 0,05)$ 
testadas, principalmente os extratos preparados em alta temperatura e aplicados a 4\%. Além disso, os valores da entropia informacional da germinação dos aquênios de alface foram aumentados por extratos de
C. pachystachya,P. leiocarpa e S. glandulatum. As curvas de germinação ao longo das $96 \mathrm{~h}$ de bioensaio (Fig. 1) reforçam estas diferenças em relação ao tratamento controle, indicando efeitos inibitórios sobre
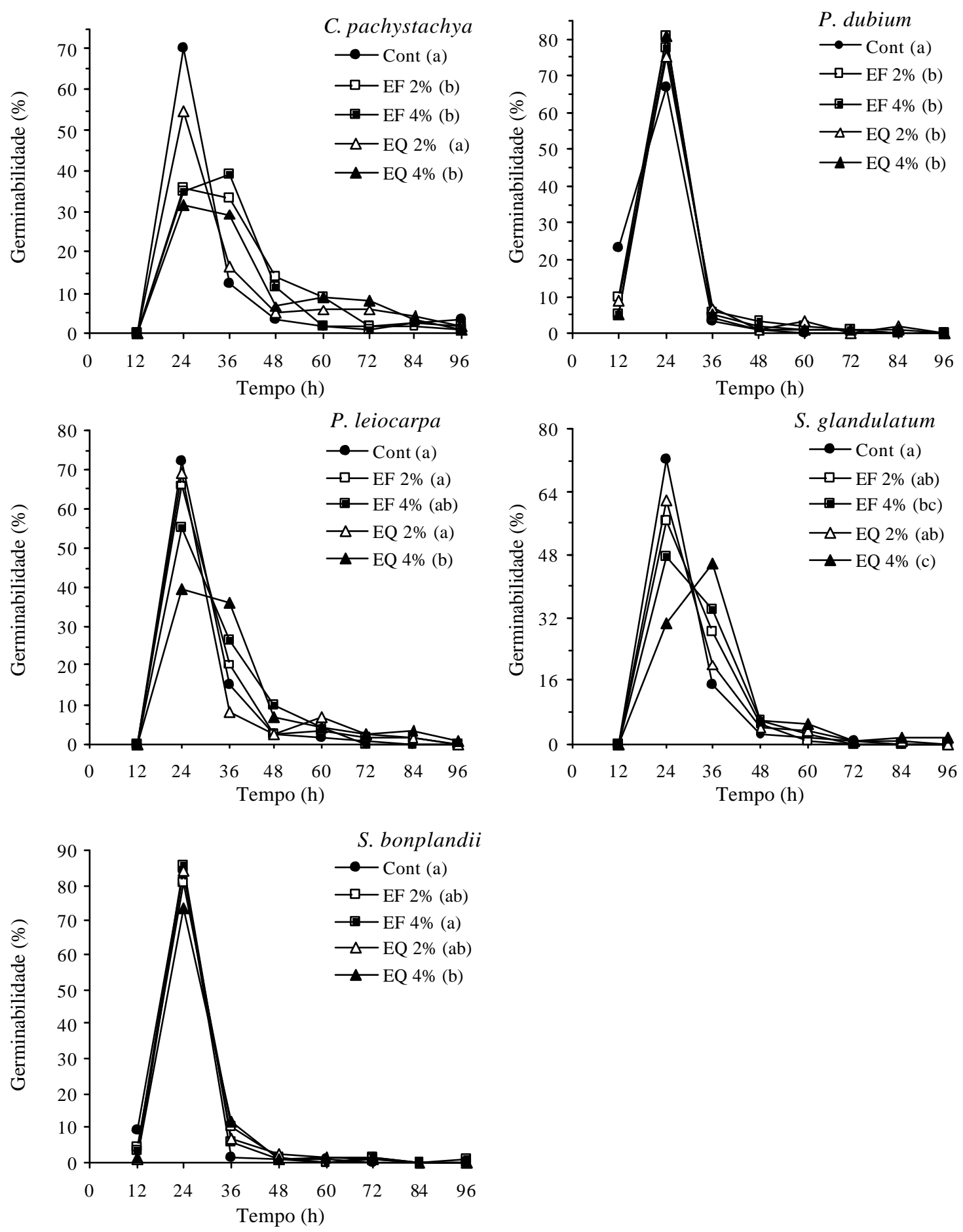

Figura 1. Germinabilidade de aquênios de alface, sob ação dos extratos foliares aquosos de Cecropia pachystachya Trec., Peltophorum dubium (Spreng.) Taub., Psychotria leiocarpa Cham. \& Schldtl, Sapium glandulatum (Vell.) Pax e Sorocea bonplandii (Baill.) Burg. Dentro de cada bioensaio, curvas de germinabilidade com as mesmas letras não diferem entre si $(\mathrm{p} \leq 0,05)$. Cont: controle (água destilada); EF $2 \%$ : extrato foliar extraído a $8{ }^{\circ} \mathrm{C}$, diluído em água a $2 \%$; EF $4 \%$ : extrato foliar extraído a $8{ }^{\circ} \mathrm{C}$, diluído em água a $4 \%$; EQ $2 \%$ : extrato foliar aquoso a $2 \%$, extraído à temperatura inicial de $80{ }^{\circ} \mathrm{C}$; EQ $4 \%$ : extrato foliar aquoso a $4 \%$, extraído à temperatura inicial de $80{ }^{\circ} \mathrm{C}$. 
as germinabilidades parciais dos aquênios de alface tratados com extratos das espécies testadas, apesar de não haver diferenças na germinabilidade final (Tab. 1). Os atrasos na germinação foram mais acentuados nas primeiras $36 \mathrm{~h}$ de bioensaio, conforme mostram as curvas da Fig. 1. Também foram constatadas diferenças significativas entre os efeitos causados na germinação dos aquênios de alface tratados com extratos a $4 \%$ de $S$. glandulatum $(\bar{t}) \mathrm{e}$ $S$. bonplandii $(G)$, preparados em alta e baixa temperatura (Tab. 1).

A proporção de aquênios viáveis que não germinaram nas condições dos bioensaios variou de $0-1,67 \%$ para o controle; $0-2,50 \%$ para os extratos preparados a frio a $2 \% ; 0-1,67 \%$ para os mesmos extratos a $4 \% ; 0-2,50 \%$ para os extratos obtidos em alta temperatura a $2 \%$ e de $0,83-2,50 \%$ para os mesmos extratos a $4 \%$.

Em relação ao crescimento inicial da alface, os extratos de todas as espécies testadas provocaram inibições nas plântulas, quando comparados ao tratamento controle. Os efeitos mais acentuados foram causados nas raízes, observando-se um gradiente de inibição que variou do tratamento com extrato obtido a frio $2 \%$ até o obtido em alta temperatura a $4 \% \mathrm{em}$ todos os bioensaios, exceto para P. leiocarpa (Fig. 2). Por outro lado, apenas os extratos de $P$. leiocarpa foram capazes de reduzir o tamanho do hipocótilo das plântulas de alface tratadas, em relação ao controle. Com exceção do bioensaio com extratos de $S$. glandulatum, os demais bioensaios apresentaram diferenças significativas no tamanho das raízes de
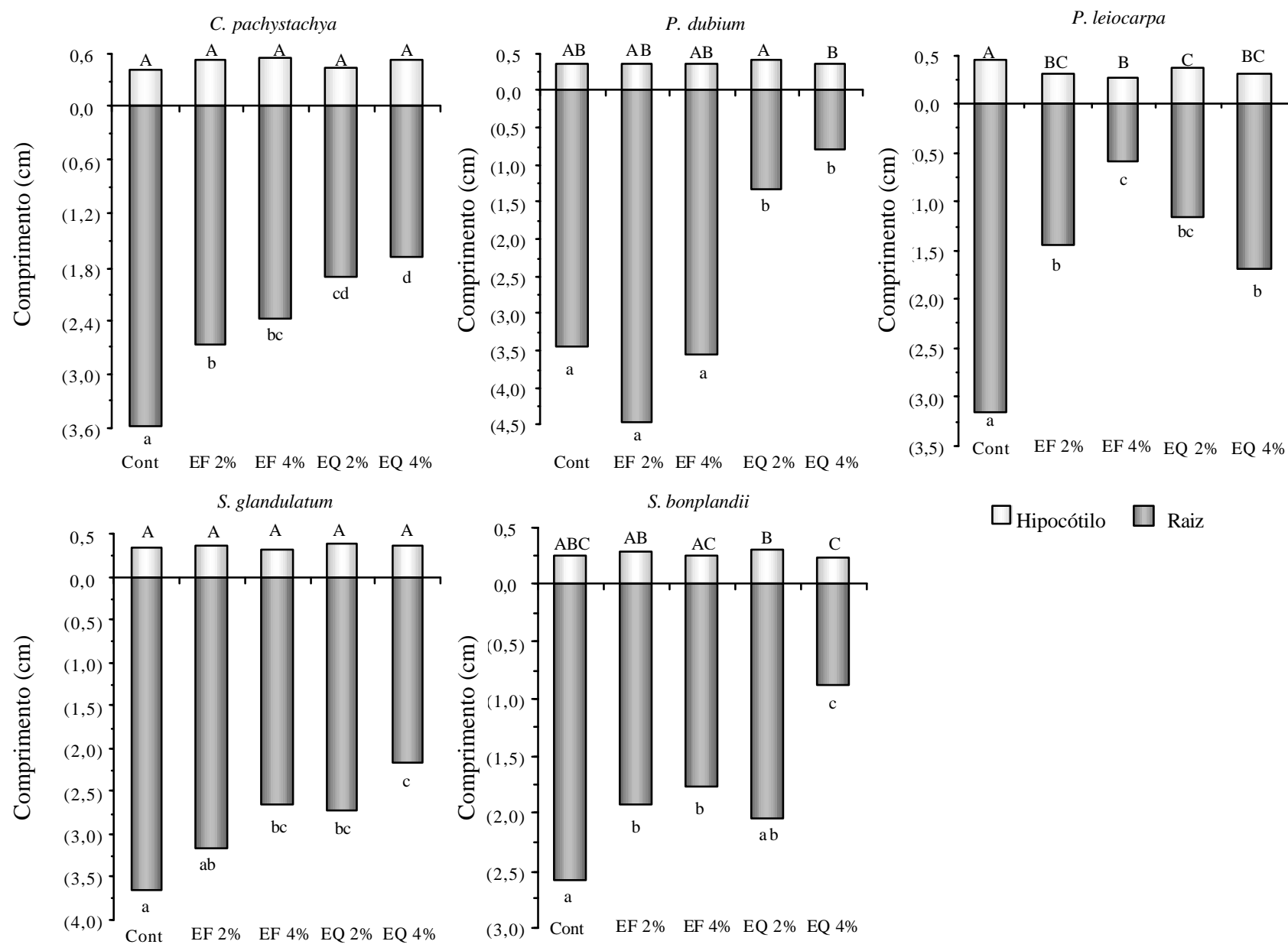

Figura 2. Influência dos extratos foliares aquosos de Cecropia pachystachya Trec., Peltophorum dubium (Spreng.) Taub., Psychotria leiocarpa Cham. \& Schldtl, Sapium glandulatum (Vell.) Pax e Sorocea bonplandii (Baill.) Burg. no crescimento inicial de plântulas de alface após $96 \mathrm{~h}$. Letras iguais, na horizontal dentro de cada bioensaio, não diferem entre si ( $\mathrm{p} \leq 0,05)$. Cont: controle (água destilada); EF $2 \%$ : extrato foliar extraído a $8{ }^{\circ} \mathrm{C}$, diluído em água a $2 \%$; EF $4 \%$ : extrato foliar extraído a $8{ }^{\circ} \mathrm{C}$, diluído em água a $4 \%$; EQ $2 \%$ : extrato foliar aquoso a $2 \%$, extraído à temperatura inicial de $80^{\circ} \mathrm{C}$; EQ $4 \%$ : extrato foliar aquoso a $4 \%$, extraído à temperatura inicial de $80^{\circ} \mathrm{C}$. 
alface entre os tratamentos com extratos de mesma concentração, preparados em baixa e alta temperatura (Fig. 2).

Em todos os tratamentos com extratos de C. pachystachya, as raízes apresentaram-se mais espessas e continham mais pêlos absorventes em relação ao controle. No bioensaio com $S$. glandulatum, também foi observada esta aparência mais espessa das raízes em todos os tratamentos, sendo que os extratos a $4 \%$ causaram escurecimento nas plântulas. $\mathrm{O}$ extrato de $P$. dubium, preparado em alta temperatura a $4 \%$; os extratos obtidos a frio a 2 e $4 \%$ e o obtido em alta temperatura a $4 \%$ de $S$. bonplandii, causaram escurecimento das raízes da alface. Esta mesma aparência foi constatada em todos os tratamentos com $P$. leiocarpa, somando-se ao aspecto frágil e quebradiço das plântulas.

Os valores iniciais de $\mathrm{pH}$ dos extratos nos bioensaios de germinação e crescimento oscilaram entre 5 e 6 , apresentando incrementos no final dos bioensaios, ficando entre 5 e 8 (Tab. 2), sendo estas mesmas faixas constatadas no tratamento controle. O potencial osmótico dos extratos foi baixo, variando de $-0,025$ a $-0,074 \mathrm{MPa}$. Os valores de resíduo dos extratos ficaram entre 0,667 e $10,0 \mathrm{mg} \mathrm{mL}^{-1}$, com maior rendimento nos extratos a $4 \%$.

A detecção de saponinas, flavonóides e taninos apresentou resultados positivos para as espécies testadas, com exceção de S. bonplandii (Tab. 3). A reação de detecção de flavonóides indicou a presença predominante de flavonas nas folhas de C. pachystachya e P. dubium.

\section{Discussão}

Alterações nas curvas de germinação, bem como nos índices de germinação indicam interferências nas reações metabólicas que culminam na germinação (Bewley \& Black 1978; Labouriau 1983). Nos bioensaios realizados, essa interferência no processo

Tabela 2. Características físico-químicas de extratos foliares aquosos de espécies nativas usados em bioensaios de crescimento e germinação de alface.

\begin{tabular}{|c|c|c|c|c|c|c|c|}
\hline & \multirow[t]{2}{*}{ Bioensaio } & \multicolumn{2}{|c|}{ Germinação } & \multicolumn{2}{|c|}{ Crescimento } & \multirow{2}{*}{$\begin{array}{c}\mathrm{PO} \\
(\mathrm{MPa})\end{array}$} & \multirow{2}{*}{$\begin{array}{l}\text { Resíduo } \\
\text { (mg mL-1) }\end{array}$} \\
\hline & & $\mathrm{pH}_{\mathrm{i}}$ & $\mathrm{pH}_{\mathrm{f}}$ & $\mathrm{pH}_{\mathrm{i}}$ & $\mathrm{pH}_{\mathrm{f}}$ & & \\
\hline \multirow[t]{5}{*}{ Cecropia pachystachya } & Controle & 5,80 & 5,00 & 5,84 & 6,00 & 0,000 & 0,000 \\
\hline & EF $2 \%$ & 5,90 & 6,00 & 5,90 & 6,00 & $-0,025$ & 2,000 \\
\hline & $\mathrm{EF} 4 \%$ & 5,81 & 7,00 & 5,81 & 7,00 & $-0,025$ & 4,000 \\
\hline & EQ 2\% & 5,88 & 6,00 & 5,91 & 7,00 & $-0,037$ & 3,333 \\
\hline & EQ $4 \%$ & 5,80 & 7,00 & 5,84 & 7,00 & $-0,049$ & 4,333 \\
\hline \multirow[t]{5}{*}{ Peltophorum dubium } & Controle & 5,45 & 6,00 & 5,40 & 6,00 & 0,000 & 0,000 \\
\hline & $\mathrm{EF} 2 \%$ & 5,66 & 6,00 & 5,67 & 6,00 & $-0,025$ & 0,667 \\
\hline & $\mathrm{EF} 4 \%$ & 5,60 & 6,00 & 5,55 & 7,00 & $-0,025$ & 1,667 \\
\hline & EQ $2 \%$ & 5,53 & 6,00 & 5,53 & 6,00 & $-0,025$ & 2,333 \\
\hline & EQ $4 \%$ & 5,47 & 6,00 & 5,45 & 6,00 & $-0,037$ & 2,667 \\
\hline \multirow[t]{5}{*}{ Psychotria leiocarpa } & Controle & 5,36 & 6,00 & 6,16 & 6,00 & 0,000 & 0,000 \\
\hline & EF $2 \%$ & 5,78 & 6,00 & 5,86 & 6,00 & $-0,037$ & 3,333 \\
\hline & $\mathrm{EF} 4 \%$ & 5,77 & 7,00 & 5,86 & 6,00 & $-0,049$ & 5,000 \\
\hline & EQ 2\% & 5,17 & 6,00 & 5,33 & 6,00 & $-0,025$ & 2,333 \\
\hline & EQ $4 \%$ & 5,50 & 7,00 & 5,61 & 7,00 & $-0,074$ & 10,000 \\
\hline \multirow[t]{5}{*}{ Sapium glandulatum } & Controle & 5,36 & 6,00 & 5,43 & 6,00 & 0,000 & 0,000 \\
\hline & EF $2 \%$ & 5,38 & 6,00 & 5,48 & 7,00 & $-0,025$ & 2,667 \\
\hline & $\mathrm{EF} 4 \%$ & 5,34 & 7,00 & 5,43 & 7,00 & $-0,037$ & 4,333 \\
\hline & EQ 2\% & 5,18 & 7,00 & 5,37 & 7,00 & $-0,025$ & 2,333 \\
\hline & EQ $4 \%$ & 5,33 & 7,00 & 5,33 & 7,00 & $-0,049$ & 5,000 \\
\hline \multirow[t]{5}{*}{ Sorocea bonplandii } & Controle & 5,54 & 7,00 & 5,51 & 6,00 & 0,000 & 0,000 \\
\hline & EF $2 \%$ & 6,11 & 8,00 & 6,08 & 7,00 & $-0,025$ & 2,000 \\
\hline & $\mathrm{EF} 4 \%$ & 6,06 & 7,00 & 6,03 & 7,00 & $-0,037$ & 4,667 \\
\hline & EQ $2 \%$ & 5,09 & 7,00 & 5,19 & 7,00 & $-0,025$ & 3,333 \\
\hline & EQ $4 \%$ & 5,35 & 7,00 & 5,63 & 7,00 & $-0,037$ & 4,000 \\
\hline
\end{tabular}

EF $2 \%$ : extrato foliar extraído a $8{ }^{\circ} \mathrm{C}$, diluído em água a $2 \%$; EF $4 \%$ : extrato foliar extraído a $8{ }^{\circ} \mathrm{C}$, diluído em água a $4 \%$; EQ $2 \%$ : extrato foliar aquoso a $2 \%$, extraído à temperatura inicial de $80^{\circ} \mathrm{C}$; EQ $4 \%$ : extrato foliar aquoso a $4 \%$, extraído à temperatura inicial de $80{ }^{\circ} \mathrm{C} ; \mathrm{pH}: \mathrm{pH}$ inicial; $\mathrm{pH}_{\mathrm{f}}$ : $\mathrm{pH}$ final; $\mathrm{PO}$ : potencial osmótico. 
Tabela 3. Detecção de aleloquímicos em extratos foliares aquosos de espécies nativas. ${ }^{1}$

\begin{tabular}{lccc}
\hline Espécie & Saponinas & Flavonóides & Taninos \\
\hline Cecropia pachystachya & + & $+*$ & + \\
Peltophorum dubium & + & $+*$ & + \\
Psychotria leiocarpa & + & - & - \\
Sapium glandulatum & + & - & + \\
Sorocea bonplandii & - & - & - \\
\hline
\end{tabular}

${ }^{1}$ Extratos aquosos de pó de folhas a $5 \%$, preparados em banhomaria; (+)presença; (-)ausência; *flavonas.

de germinação da alface foi constatada, sendo que os extratos causaram atraso na germinação dos aquênios, o que foi visualizado nas alterações das curvas de germinação e no tempo médio de germinação. Além disso, os extratos provocaram aumentos na entropia informacional, causados por aquênios com germinação mais lenta. Aumentos neste índice indicam perda de sincronia nas reações metabólicas da germinação (Labouriau \& Agudo 1987), demonstrando heterogeneidade na fisiologia dos aquênios tratados.

Nos estudos alelopáticos, a germinabilidade é um índice muito usado, embora não demonstre outros aspectos do processo de germinação, como atrasos, já que envolve apenas resultados finais, ignorando períodos de germinação inativa no decorrer do bioensaio (Chiapuso et al. 1997). Muitas vezes, o que se observa são efeitos significativos de extratos sobre o tempo médio e entropia de germinação e nenhuma diferença na germinabilidade, em relação ao controle (Ferreira \& Aqüila 2000), sendo que o mesmo foi verificado nos bioensaios realizados com as cinco espécies testadas.

As alterações no padrão de germinação podem resultar de diversos efeitos causados em nível primário. Entre elas, Ferreira \& Aqüila (2000) destacam alterações na permeabilidade de membranas, na transcrição e tradução do DNA, no funcionamento de mensageiros secundários, na respiração, devido ao seqüestro de oxigênio, na conformação de enzimas e receptores, ou ainda pela combinação destes fatores.

Apesar de a germinação ter sido afetada, o crescimento inicial da alface sofreu efeitos mais acentuados por parte da maioria dos extratos. As substâncias presentes nos extratos foram capazes de inibir o crescimento das plântulas, além de causarem alterações no aspecto morfológico das mesmas.

Vários estudos de alelopatia revelam efeitos inibitórios de extratos aquosos, principalmente sobre a raiz primária. Os resultados obtidos também demonstram isto, sendo que poucos extratos causaram reduções da parte aérea. Alguns autores sugerem um efeito mais acentuado sobre as raízes devido ao contato mais íntimo destas com a solução de aleloquímicos (Chung et al. 2001).

Os efeitos alelopáticos podem variar quanto à sua intensidade, visto que a ação dos aleloquímicos é condicionada por diversos fatores, tais como concentração, temperatura e outras condições ambientais. Geralmente, os efeitos causados tendem a ser dependentes da concentração dos aleloquímicos, ou seja, tendem a ser mais acentuados em concentrações mais altas, sendo essa tendência observada nos bioensaios de crescimento. Entretanto, Reigosa et al. (1999) afirmam que os efeitos alelopáticos podem escapar deste padrão, já que os efeitos observados resultam do somatório de uma série de alterações moleculares. Os efeitos de extratos de $P$. leiocarpa sobre as raízes de alface reforçam esta idéia.

A ação tóxica dos aleloquímicos presentes nos extratos também foi constatada na aparência das plântulas. Anomalias morfológicas e perda de vigor das plântulas de alface já foram demonstradas numa investigação com extratos de Ilex paraguariensis A. St.-Hil. (Aqüila 2000). Muitas fitotoxinas são capazes de afetar a morfologia e a anatomia de plântulas, o que pode ser evidenciado pelo endurecimento e escurecimento de ápices radiculares, fragilidade e aumento de ramificações (Pellissier 1993; Inderjit 1996; Cruz-Ortega et al. 1998).

De acordo com Miró et al. (1998), plântulas de milho tratadas com extratos de frutos de Ilex paraguariensis apresentaram redução no tamanho das raízes, além de menor número de pêlos absorventes. Contudo, nos bioensaios de crescimento com extratos de $C$. pachystachya e $S$. glandulatum aplicados à alface, foi visualizada maior densidade de pêlos nas raízes das plântulas, bem como maior espessamento dessas. Pode-se sugerir que essa aparência tenha sido causada pelo menor tamanho das raízes nos tratamentos, sendo contudo, fundamental uma análise mais detalhada e um método de avaliação quantitativa para confirmar estes efeitos.

Além das reações de detecção para saponinas, flavonóides e taninos, outros estudos também demonstraram a presença de vários metabólitos secundários nas folhas das espécies avaliadas (Hano et al. 1995; Elisabetsky et al. 1997; Marchiori 1997; Simões et al. 1998; Lorenzi 2000; Gonzalez et al. 2001; 
Backes \& Irgang 2002; Henriques et al. 2004), que podem ter sido responsáveis pelos efeitos alelopáticos, caso tenham sido extraídos. Contudo, deve-se frisar que nem sempre essas substâncias podem atuar como aleloquímicos, mesmo estando presentes nas plantas. A caracterização físico-química dos extratos demonstrou que o $\mathrm{pH}$, o potencial osmótico e o resíduo estão dentro do que se considera adequado para a germinação e o crescimento da alface (Baskin \& Baskin 1998; Elakovich 1999; Aqüila 2000). Em vista disto, pode-se descartar a possibilidade da interferência destes fatores nos resultados, reforçando a idéia de que substâncias químicas foram extraídas e apresentaram efeito tóxico sobre a germinação e o crescimento da alface.

De acordo com Einhellig (1999), os efeitos alelopáticos resultam da ação de várias substâncias que atuam em conjunto, visto que, em geral, os aleloquímicos são encontrados em baixas concentrações no meio ambiente. Os extratos aquosos são misturas que podem conter substâncias de várias classes como terpenóides, fenólicos, alcalóides, aminoácidos não protéicos, dentre outras, e que apresentam efeitos complexos sobre a alface, ainda não completamente elucidados. Adicionalmente, resultados positivos para alelopatia, obtidos em laboratório, podem não se repetir em condições naturais, devido à ocorrência simultânea de diversos fatores bióticos e abióticos que podem mascarar este fenômeno.

De acordo com os resultados obtidos no presente estudo, pode-se concluir que Cecropia pachystachya, Peltophorum dubium, Psychotria leiocarpa, Sapium glandulatum e Sorocea bonplandii apresentam potencial alelopático. A conclusão definitiva de que estas espécies sejam alelopáticas em condições naturais está associada a uma investigação mais ampla, que inclui outras abordagens experimentais, principalmente testes a campo.

\section{Agradecimentos}

Aos biólogos Adriano Scherer e Raquel Lüdtke, pelo apoio nas coletas e no acompanhamento dos bioensaios; ao Laboratório de Fisiologia Vegetal do Departamento de Botânica da UFRGS, pela infraestrutura cedida.

\section{Referências bibliográficas}

Anaya, A.L. 1999. Allelopathy as a Tool in the Management of Biotic Resources in Agroecosystems. Critical Reviews in Plant Sciences 18(6): 697-739.
Aqüila, M.E.A. 2000. Efeito alelopático de Ilex paraguariensis A. St.-Hil. na germinação e crescimento inicial de Lactuca sativa L. Iheringia, Série Botânica 53: 51-66.

Backes, P. \& Irgang, B.E. 2002. Árvores do sul: guia de identificação e interesse ecológico. Rio de Janeiro, Instituto Souza Cruz-Clube da Árvore.

Baskin, C.C. \& Baskin, J.M. 1998. Seeds: ecology, biogeography and evolution of dormancy and germination. New York, Academic Press.

Bewley, J.D. \& Black, M. 1978. Physiology and biochemistry of seeds, in relation to germination. v. 1. Berlin, SpringerVerlag.

Brasil. 1992. Ministério da Agricultura e Reforma Agrária. Regras para análise de sementes. Brasília, SNDA/ DNDV/CLAV.

Chiapusio, G.; Sánchez, A.M.; Reigosa, M.J.; González, L. \& Pellissier, F. 1997. Do germination indices adequately reflect allelochemical effects on the germination process? Journal of Chemical Ecology 23: 2445-2453.

Chou, C.H. 1986. The role of allelopathy in subtropical agroecosystems in Taiwan. Pp. 57-73. In: A.L. Putnam \& C.S. Tang (eds.). The science of allelopathy. New York, John Wiley \& Sons.

Chou, C.H. 1999. Roles of allelopathy in plant biodiversity and sustainable agriculture. Critical Reviews in Plant Sciences 18(5): 609-636.

Chung, I.M.; Ahn, J.K. \& Yun, S.J. 2001. Assesment of allelopathic potential of barnyard grass (Echinochloa crus-gall) on rice (Oriza sativa L.) cultivars. Crop Protection 20: 921-928.

Cruz-Ortega, R.; Anaya, A.L.; Hernández-Bautista, B.E. \& Laguna-Hernández, G. 1998. Effects of allelochemical stress produced by Sicyios deppei on seedling root ultrastructure of Phaseolus vulgaris e Curcubita ficifolia. Journal of Chemical Ecology 24(12): 2039-2057.

Einhellig, F.A. 1999. An integrated view of allelochemicals amid multiple stresses. Pp. 479-494. In: Inderjit; K.M.M. Dakshini \& C.L. Foy (eds.). Principles and Practices in Plant Ecology. Boca Raton, CRC Press.

Elakovich, S.D. 1999. Bioassays applied to allelopathic herbaceous vascular hydrophytes. Pp. 45-56. In: Inderjit; K.M.M. Dakshini \& C.L. Foy (eds.). Principles and Practices in Plant Ecology. Boca Raton, CRC Press.

Elisabetsky, E.; Amador, T.A.; Leal, M.B.; Nunes, D.S.; Carvalho, A.C.T. \& Verotta, L. 1997. Merging ethnopharmacology with chemotaxonomy: an approach to unveil bioactive natural products. The case of Psychotria alkaloids as potential analgesics. Ciência e Cultura 49(5/6): 378-385.

Falkenberg, M.B.; Santos, R.I. \& Simões, C.M.O. 2003. Introdução à análise fitoquímica. Pp. 229-245. In: C.M.O. Simões; E.P. Schenkel; G. Gosmann; J.C.P. Mello; L.A. Mentz \& P.R. Petrovick (eds.). Farmacognosia: da planta ao medicamento. $5^{\text {a }}$ ed. Porto Alegre, Ed. UFRGS.

Ferreira, A.G. \& Aqüila, M.E.A. 2000. Alelopatia: uma área emergente da ecofisiologia. Revista Brasileira de Fisiologia Vegetal 12(Edição especial): 175-204. 
Ferreira, A.G. Aqüila, M.E.A.; Jacobi, U.S. \& Rizvi, V. 1992. Allelopathy in Brazil. Pp. 243-250. In: S.J.H. Rizvi \& V. Rizvi (eds.). Allelopathy: basic and applied aspects. London, Chapman \& Hall.

Gonzalez, F.G.; Portela, T.Y.; Stipp, E.J. \& Di Stasi, L.C. 2001. Antiulcerogenic and analgesic effects of Maytenus aquifolium, Sorocea bomplandii and Zolernia ilicifolia. Journal of Ethnopharmacology 77: 41-47.

Hano, Y.; Yamanaka, J.; Momose, Y. \& Nomura, T. 1995. Sorocerols C-F, four new isoprenylated phenols from the root bark of Sorocea bonplandii Baillon. Heterocycles 41(12): 2811-2821.

Henriques, A.T.; Lopes, S.O.; Paranhos, J.T.; Gregianini, T.S.; Von Poser, G.L.; Fett-Neto, A.G.; Schripsema, J. 2004. $N$, b-D-Glucopyranosyl vincosamide, a light regulated indole alkaloid from the shoots of Psychotria leiocarpa. Phytochemistry 65(4): 449-454.

Inderjit. 1996. Plant phenolics in allelopathy. The Botanical Review62(2): 186-202.

Labouriau, L.F.G. 1983. A germinação das sementes . Departamento de Assuntos Científicos e Tecnológicos da Secretaria Geral da Organização dos Estados Americanos, Washington. Série Biologia, Monografia 24.

Labouriau, L.F.G. \& Agudo, M. 1987. On the physiology of seed germination in Salvia hispanica L. I. Temperatura effects. Anais da Academia Brasileira de Ciências 59(1): 37-56.

Lorenzi, H. 2000. Árvores brasileiras. v. 1. $3^{\mathrm{a}}$ ed. Nova Odessa, Instituto Plantarum.

Macharia, C. \& Peffley, E.B. 1995. Suppression of Amaranthus spinosus and Kochia scoparia: evidence of competition of allelopathy inAllium fistulosum. Crop Protection 14(2): 155-158.

Manly, B.F.J. 1991. Randomization and Monte Carlo methods in biology. London, Chapman \& Hall.

Marchiori, J.N.C. 1997. Dendrologia das angiospermas: leguminosas. Santa Maria, Ed. UFSM.

Miró, C.P.; Ferreira, A.G. \& Aqüila, M.E.A. 1998. Alelopatia de frutos de erva-mate (Ilex paraguariensis) no desenvolvimento do milho. Pesquisa Agropecuária Brasileira 33(8): 1261-1270.
Pellissier, F. 1993. Allelopathic inhibition of spruce germination. Acta Oecologica 14(2): 211-218.

Pillar, V.D. 2001. MULTIV, Software for Multivariate Exploratory Analysis and Randomization Testing. Departamento de Ecologia. Porto Alegre, Universidade Federal Rural do Rio Grande do Sul.

Pillar, V.D. \& Orlóci, L. 1996. On randomization testing in vegetation science: multifactor comparisons of relevé groups. Journal of Vegetation Science 7: 585-592.

Putnam, A.R. \& Duke, W.B. 1974. Biological Suppression of Weeds: Evidence for Allelopathy in Accession of Cucumber. Science 185: 370-372.

Reigosa, M.J.; Sánchez-Moreiras, A. \& González, L. 1999. Ecophysiological approach in allelopathy. Critical Reviews in Plant Sciences 18(5): 577-608.

Rice, E.L. 1984. Allelopathy. $2^{\mathrm{a}}$ ed. New York, Academic Press.

Rizvi, S.J.H.; Haque, H.; Singh, V.K. \& Rizvi, V. 1992. A discipline called allelopathy. Pp. 1-10. In: S.J.H. Rizvi \& V. Rizvi (eds.). Allelopathy: basic and applied aspects. London, Chapman \& Hall.

Rutherford, M.C. \& Powrie, L.W. 1993. Allelochemic control of biomass allocation in interacting shrub species. Journal of Chemical Ecology 19(5): 893-906.

Salisbury, F.B. \& Ross, C. 1992. Plant Physiology. Belmont, Ed. Wadsworth.

Scrivanti, L.R.; Zunnino, M.P. \& Zygadlo, J.A. 2003. Tagetes minuta and Schinus areira essential oils as allelopathic agents. Biochemical Systematics and Ecology 31:563-572.

Simões, C.M.O.; Mentz, L.A. Schenckel, E.P.; Irgang, B.E. \& Stehmann, J.R. 1998. Plantas da medicina popular no Rio Grande do Sul. $5^{\text {a }}$ ed. Ed. Porto Alegre, Universidade Federal Rural do Rio Grande do Sul.

Soares, G.L.G. \& Vieira, T.R. 2000. Inibição da germinação e do crescimento radicular de alface (cv. "Grand Rapids") por extratos aquosos de cinco espécies de Gleicheniaceae. Floresta e Ambiente 7(1): 180-197.

Vyvyan, J.R. 2002. Allelochemicals as leads for new herbicides and agrochemicals. Tetrahedron 58: 1631-1646.

Whittaker, R.W. \& Feeny, P.P. 1971. Allelochemics: chemical interactions between species. Science 171(3973): 757-769. 